\title{
A system dynamics approach for hospital waste management in a city in a developing country: the case of Nablus, Palestine
}

\author{
Issam A. Al-Khatib \& Derar Eleyan \& Joy Garfield
}

\author{
I. A. Al-Khatib Institute of Environmental and Water Studies, Birzeit University, P.O. Box \\ 14BirzeitWest Bank, Palestine e-mail: ikhatib@birzeit.edu \\ D. Eleyan Computer Science Department, Birzeit University, West Bank, Palestine \\ J. Garfield Worcester Business School, University of Worcester, Worcester, UK
}

\begin{abstract}
Hospitals and health centers provide a variety of healthcare services and normally generate hazardous waste as well as general waste. General waste has a similar nature to that of municipal solid waste and therefore could be disposed of in municipal landfills. However, hazardous waste poses risks to public health, unless it is properly managed. The hospital waste management system encompasses many factors, i.e., number of beds, number of employees, level of service, population, birth rate, fertility rate, and not in my back yard (NIMBY) syndrome. Therefore, this management system requires a comprehensive analysis to determine the role of each factor and its influence on the whole system. In this research, a hospital waste management simulation model is presented based on the system dynamics technique to determine the interaction among these factors in the system using a software package, ithink. This model is used to estimate waste segregation as this is important in the hospital waste management system to minimize risk to public health. Real data has been obtained from a case study of the city of Nablus, Palestine to validate the model. The model exhibits wastes generated from three types of hospitals (private, charitable, and government) by considering the number of both inpatients and outpatients depending on the population of the city under study. The model also offers the facility to compare the total waste generated among these different types of hospitals and anticipate and predict the future generated waste both infectious and non-infectious and the treatment cost incurred.
\end{abstract}

Keywords Hazardous waste, Hospitals, Generation rate, System dynamics, Developing countries, Palestine.

\section{Introduction}

\section{Background}

Hospitals and healthcare centers are among leading sources of infectious and non-infectious waste in any country. They provide patient care services, and it is their duty to look after public health and make sure that medical waste is treated and disposed of in proper ways directly through patient care or indirectly by ensuring a clean, healthy environment for their employees and the community. Governments have enacted different laws and regulations to organize the disposal of waste together with treatments to minimize the risks on public health, which can produce extra government expenditure. It is highly important to recognize the types of infectious and non-infectious waste and 
to segregate, collect, and dispose or treat them in an acceptable manner. Lots of research has been conducted in this regard, and focus on waste management includes waste generation, segregation, collection, and disposal. This research focuses on the current situation of waste generation and does not anticipate and predict the future quantities and how much will it cost to treat and dispose of waste. System dynamics modeling is a famous technique used to simulate the current situation and predict the future to portray a clear and obvious picture of waste generation and can assist the decision maker in validating decisions and their consequences. This research is conducted using data extracted from different types of hospitals according to their level of services and finds out the waste generated dependent on the number of beds together with other variables.

\section{Hospital waste management}

Hospital waste is produced from different sources and is mainly generated when treating, preventing, and diagnosing or conducting research on human and animal disease. On a yearly basis, huge quantities estimated in millions of tons of medical waste are produced by healthcare facilities throughout the world (Bdour et al. 2007; Birpinar et al. 2009; Cheng et al. 2009, 2010; Yong et al. 2009). Developed countries produce much more medical waste than developing countries due to the technology used in the different healthcare centers making medical waste a critical problem attracting more attention (Abd El-Salam 2010; Manga et al. 2011).

Treating or disposing of hospital waste presents environmental and public health risks and can contribute to the spread of infectious diseases. Diseases including the human immunodeficiency virus (HIV), hepatitis viruses B and C, cholera, and diphtheria are known among many others. Such diseases can be easily transferred to human beings through medical waste if it is not properly managed (Pruss-Ustun et al. 2005; Shiferaw et al. 2012).

According to the absence of universal consent, different terms are normally used to define waste generated from health centers and hospitals. Some researchers use the term health care waste; others use medical or clinical waste (Abd El-Salam 2010; Prem Ananth et al.2010; Patwary et al. 2011; Hossain et al. 2011). Therefore, in this paper, hospital solid waste is divided into two components: general (non-hazardous) waste and hazardous waste.

Normally, wastes generated from hospitals and medical centers have both hazardous and nonhazardous components. Olko and Winch (2002) found that in England, approximately $50 \%$ of healthcare waste generated annually could be classified as municipal (non-hazardous) waste. Alagöz and Kocasoy (2008) indicated that $65 \%$ of healthcare waste generated is municipal (general) waste, thus only $35 \%$ of this waste could be considered as a hazardous waste and should be successfully segregated and diverted with special attention. In spite of the small proportion of hazardous healthcare waste annually generated, there are still poor practices in segregating general waste from hazardous healthcare waste streams, which consequently show that the entire waste is potentially infectious. Many studies in waste management indicate the adoption of much more stringent segregation practices especially after enacting hazardous waste regulations (DEFRA 2005). Surveys in developing countries showed scarcity of segregation in this context; Bendjoudi et al. (2009) showed that the general waste fraction represents $75-90 \%$ of the total Algerian healthcare waste. Also, segregation could be an important economic factor due to large differences in costs associated with healthcare waste disposal, as Lee et al. (2004) showed in his study conducted in typical Massachusetts' city hospitals. 
Healthcare waste management is similar to any waste management system; it includes generation, segregation, collection, storage, treatment, and final disposal (Ciplak and Barton 2012). Hospital waste, if not properly managed, consequently becomes a leading cause of death worldwide, where many infectious diseases once thought conquered are increasing and continue to be a serious public health problem. This raises the necessity for hospital waste to be carefully and properly managed (Mohamed et al. 2009; Taghipoura and Mosaferi 2009; Haylamicheal et al. 2011). Healthcare waste management is mainly concerned with health and safety hazards associated with the handling of waste generated from healthcare centers (Blenkharn 2006). The major risks can be summarized as follows: personnel risks due to their involvement in handling waste containing blood or bodily fluids, final disposal or incineration of waste, pharmacy and laboratory activities, public health risks through transportation of hazardous and infectious waste, and the pollution of air, water, and soil (Health and Safety Executive (HSE) 2008; Askarian et al. 2010).

Khalaf (2009) shows in a study of Jenin District hospitals that staffs are still unqualified in medical waste collection and lack temporary waste storage areas. Also, healthcare waste is disposed of in centralized sanitary landfill, which is designated to domestic waste and not for healthcare waste. The study also shows the scarcity of legislation concerning the management and treatment of medical waste, and the medical waste generated is dumped with general waste. The study highlights the necessity of sustained collaboration among all key actors (government, hospital, and waste managers) to implement a safely reliable medical waste strategy besides the legislation and policy formation especially the monitoring and enforcement process.

Hospital managers usually consider the hospital waste generation rate as an important indicator to evaluate the performance of hospital waste management. This indicator is used to measure achievements and to perform comparisons between hospitals. When hospital managers aim to measure hospital waste generation, they consider different factors, such as purchasing, handling, segregation, collection, treatment, and disposal. The comparison process between hospitals is quite a complicated process as hospitals differ in size, type, specialization, technical level, quality, and efficiency (Debere et al. 2013).

\section{System dynamics models and its applications}

In the 1960s, Jay Forrester introduced system dynamics modeling at the Massachusetts Institute of Technology as a methodology for the modeling and simulation of complex systems for business management decision making. A waste management system is a good example of a complex system to be simulated using system dynamics, as it encompasses a variety of variables with interrelationships having variable values over a period of time. System dynamics has the capability to deal with and monitor assumptions about system structures and the effects of changes on theses sub-systems in a stringent fashion (Chaerul etal. 2008) and generate simulated scenarios depending on the variations of variables.

System dynamics has been used for a long time as a simulation tool in different aspects of life. Areas include global environmental sustainability (Forrester 1971; Meadows et al. 1992), environmental sustainability in agricultural development (Saysel and Barlas 2001), modeling strategies for promoting agricultural development (Drew 1990), regional sustainable development issues (Bach and Saeed 1992; Saeed1994), environmental management (Mashayekhi 1990; Sudhir et al. 1997), and ecological modeling (Saysel and Barlas 2001). 
The feedback concept and feedback loops, which are based on control theory, are the core concepts of the system dynamics approach (Bala1999). Feedback loops are converted into a stock and flow model, which constitutes three main building blocks: stock, flow, and convertor. The stock variable represents an accumulated state in the target system and is symbolized by a rectangle. Flow variables represent the rate of change in the stock and the activities, and decision functions in the same system are symbolized by a valve. A converter is an intermediate variable used for miscellaneous calculations and symbolized by a circle. Connectors are required to connect the aforementioned blocks with each other to represent interlinkages and effects between them (Bala 1999). The original simulation computer model was developed and used as a part of thesis (Sufian 2001) using STELLA Research software (HPS 1996), which is a well-known software designed for dynamic feedback modeling of complex systems. Full details are available in Sufian (2001).

Chaerul et al. (2008) proposed a hospital waste system dynamics model. This model showed a direct proportion between the number of beds available and the hospital waste generation rate. A segregation process is needed to separate hazardous from non-hazardous waste. This process is affected by the knowledge and experience of hospital staff. The collected waste is either general or infectious waste, which is treated and disposed of at a final disposal site. The disposal rate affects the lifetime of the disposal site, as increasing the disposal rate shortens the lifetime of the disposal site. Finding a new disposal site in a highly populated area is quite difficult and results in increasing the not in my backyard (NIMBY) syndrome. The model also showed that public education programs and raising awareness by various forms of media on disposal issues could reduce the NIMBY syndrome. Also, more expenditure and investment on health services will positively affect and increase the life expectancy as it reduces the health risks relevant to untreated hazardous waste.

Ciplak and Barton (2012) proposed another system dynamics model. This model has been developed by relying on both literature review and authors' observations from a case study in Istanbul. The literature review focused on the factors affecting origin, definition, composition, and weight flows of health care waste. The model depicted sub-models using a detailed breakdown of parameters, which reflected the availability of data for Istanbul. The model also showed that healthcare waste generation relied on the population and capacity of the hospital in terms of bed availability for both inpatients and outpatients. The model also depicted the segregation rate, which is used to separate hazardous waste from non-hazardous waste, which is affected by the knowledge of the hospital's staff and visitors at the point of generation. The proposed system dynamics model will portray the phases of hospital waste management and the associated factors influencing each phase and how to handle them efficiently.

\section{Methodology}

Nablus city was the study area of the case study in this paper. Four hospitals were selected: two of them are government funded, one private, and one charitable hospital. The main part of this study was the measurement of generated solid waste and its components resulting from the four hospitals. Solid waste was divided into two categories: general (non-hazardous) and hazardous waste. The measurements included both the weight of general and hazardous wastes resulting from four hospitals in the study area over seven consecutive days in each hospital. The essential factors, which were considered in the model, are the number of beds in each hospital, type of hospital, the service level of the hospital, the number of inpatients, number of outpatients, number of staff at the 
hospital, and hospital departments through cooperation with the administrative director in each of the four hospitals.

A causal loop diagram has been constructed to exhibit the causal relations between the variables under study in the population and how it is affected by both the birth and death rates. It also portrays the inpatient and the outpatient waste generation, waste treated, and waste disposal. A stock and flow diagram has been generated from the causal loop diagram using ithink software. Furthermore, the stock and flow model was tested using the data collected from the different hospitals under study.

The research focuses on building a simulated system dynamics model for hospital waste management to be used as a prediction tool to assist decision makers dealing with waste management to plan accordingly. The model shows different future scenarios of the hospital waste situation in Palestine, considering Nablus city as a case study and considering different relevant factors.

The model also shows the quantities generated of each type of hospital waste for the next 10 to 20 years by considering the population, birth rate, death rate, number of beds, number of hospital's employees, number of patients, and level of service among hospitals. The decision makers will rely on this tool to examine different approaches to treat and recycle waste depending on the recycling rate. The model is validated using collected data from Nablus city hospitals. The results can be generalized and portray the management of hospital waste in a developing country.

The proposed system dynamics model for hospital waste management in developing countries. The proposed model is developed using the system dynamics modeling methodology. Firstly, a causal loop diagram has been developed as shown in Fig. 1.

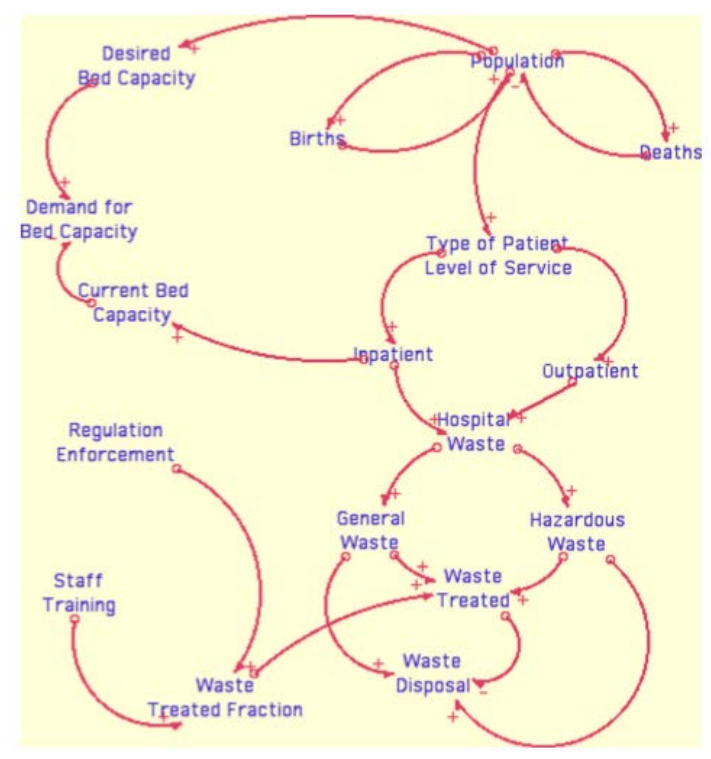

Fig. 1 Causal loop diagram of healthcare waste management system

This diagram shows the causal relations between the relevant variables (factors). It shows that the waste generation is accumulated from inpatient and outpatient generated waste. However, the inpatient waste generation is already affected by the current bed capacity in a hospital. It also shows that waste separation is affected by regulation enforcement and training. Secondly, a stock and flow 
diagram (Fig. 2) has been developed on the proposed causal loop diagram and simulated using real data.

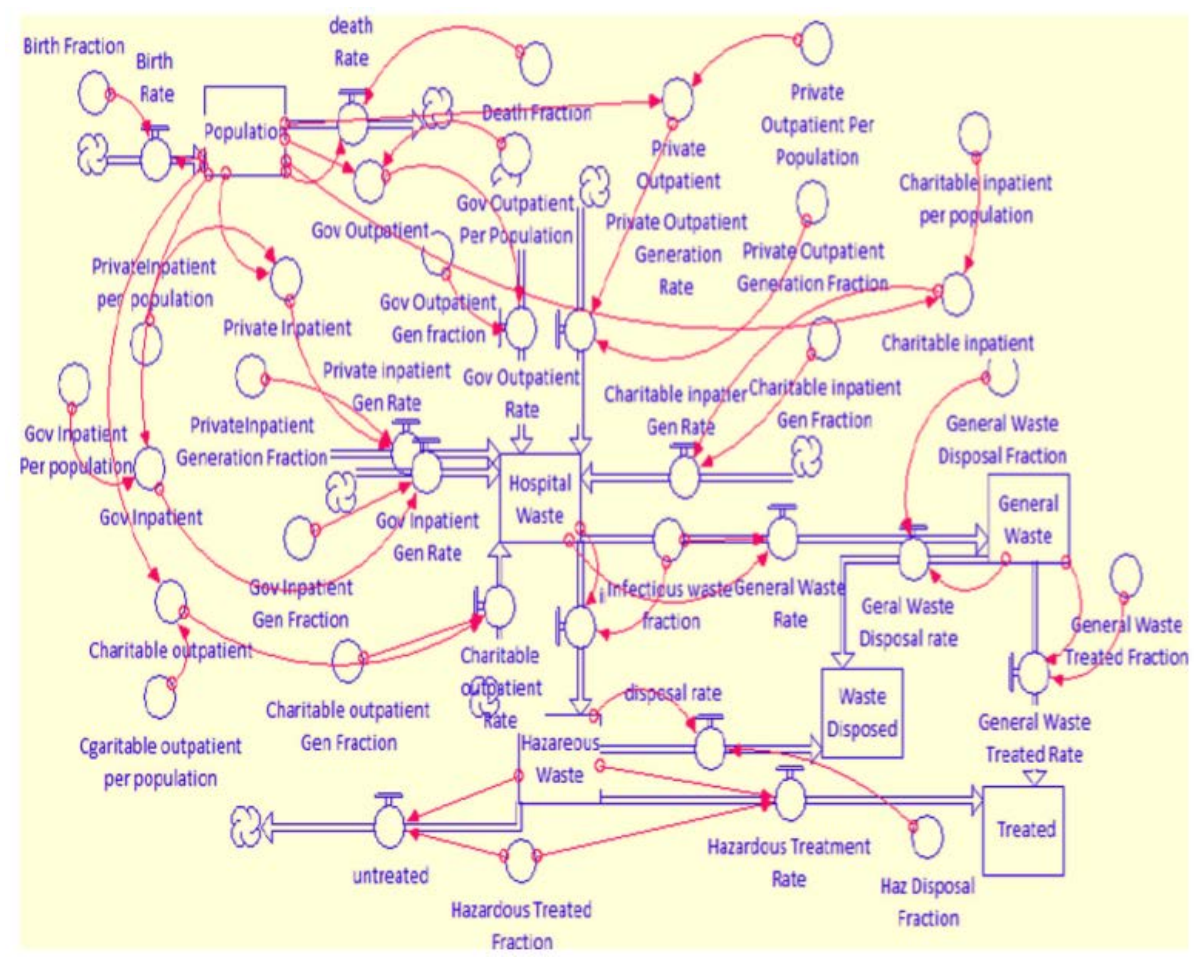

Fig. 2 Hospital waste stock and flow diagram

Table 1 classifies the waste generated according to the level of service, for example, government hospitals generate less waste than private hospitals and the private hospital generates waste more than the charitable one.

Table 1 Hospital characteristics and average daily waste generation in 2013

\begin{tabular}{lllll}
\hline Variables & \multicolumn{3}{l}{ Hospitals } & \\
\cline { 2 - 5 } & Rafidia & Al Watani & Al Ittihad & Al Arabi \\
\hline Level of service & Gov. (1) & Gov. (1) & $\begin{array}{c}\text { Charitable } \\
(2)\end{array}$ & $\begin{array}{c}\text { Private } \\
(3)\end{array}$ \\
$\begin{array}{l}\text { Number of beds } \\
\begin{array}{l}\text { Number of } \\
\text { employees }\end{array}\end{array}$ & 204 & 110 & 50 & 100 \\
$\begin{array}{c}\text { Mean of general } \\
\text { waste generation } \\
\text { (kg/day) }\end{array}$ & 676.4 & 453.0 & 176.47 & 328.21 \\
$\begin{array}{c}\text { Mean of hazardous } \\
\text { waste generation } \\
\text { (kg/day) }\end{array}$ & 137.0 & 94.0 & 37.35 & 73.48 \\
$\begin{array}{c}\text { Mean of hazardous } \\
\text { to general } \\
\text { hospital solid } \\
\text { waste generation } \\
\text { ratio (\%) }\end{array}$ & 20.3 & 20.8 & 21.4 & 22.3 \\
\hline
\end{tabular}

The table also shows that the average fraction of hazard/ general waste is nearly the same for government, private, and charitable hospitals. It can be clearly noticed from Table 1 that the mean hazardous to general hospital solid waste generation ratio is nearly the same for all hospitals (private, government, and charitable). This mean will be used in the simulation model to verify the hazardous waste from the general waste. Table 2 exhibits the general and hazardous waste 
generation fractions for both inpatients and outpatients in government, charitable, and private hospitals.

Table 2 Daily quantities of healthcare waste generation rates in the surveyed hospitals in Nablus city, Palestine in 2013

\begin{tabular}{llll}
\hline $\begin{array}{l}\text { Hospital } \\
\text { level of } \\
\text { Service }\end{array}$ & Generation rate & $\begin{array}{l}\text { General } \\
\text { waste }\end{array}$ & $\begin{array}{l}\text { Hazardous } \\
\text { waste }\end{array}$ \\
\hline Government & $\mathrm{kg} /$ inpatients/day & 2.03 & 0.293 \\
& $\begin{array}{l}\mathrm{kg} / \text { outpatients/day } \\
\text { kg/total patient/ }\end{array}$ & 0.65 & 0.088 \\
& $\begin{array}{c}\text { day } \\
\mathrm{kg} / \text { inpatients/day }\end{array}$ & 4.45 & 0.275 \\
Charity & $\mathrm{kg} /$ outpatients/day & 2.18 & 0.87 \\
& $\mathrm{~kg} /$ total patient/ & 3.32 & 0.51 \\
& $\begin{array}{c}\text { day } \\
\text { Pg/inpatients/day }\end{array}$ & 7.57 & 1.64 \\
& $\mathrm{~kg} /$ outpatients/day & 3.35 & 0.56 \\
& $\mathrm{~kg} /$ total patient/ \\
day & 5.45 & 1.10 \\
& & & \\
\hline
\end{tabular}

The employee patient ratio in government hospitals equals 0.8 , while in the private hospital, it equals 3.2, which means the level of service in the private hospital is much better than in the government one. Therefore, the waste generation rate in the private hospital is also greater than the government hospitals.

Total outpatients visiting government hospitals on a yearly basis equals 0.82 of the total population. While government inpatients equal to 0.1 of the total population, the private outpatients and inpatients per population are 0.046 and 0.023 , respectively. Also, the charitable inpatient and outpatient ratios are 0.023 and 0.033 , respectively (Ministry of Health, 2012). The disposal and treated fractions for both general and hazardous waste are clearly obtained from the study. For example, $83.1 \%$ of general waste is disposed of, while $16.9 \%$ of hazardous waste is disposed of. There is no treatment of general waste, while $20.0 \%$ of the total hazardous waste is treated. Debere et al. (2013) showed that generated waste from inpatients and outpatients was 3.9 and $2.77 \mathrm{~kg}$ of waste per day, respectively, in private hospitals in Ethiopia. While in Palestine, the waste generated from private hospitals for both inpatients and outpatients are 7.57 and $3.35 \mathrm{~kg}$, respectively. This shows that inpatients in Palestine generate higher levels of waste than in Ethiopia. However, outpatients in both countries generate waste close to each other as government hospitals both in Palestine and Ethiopia generated $0.65 \mathrm{~kg} /$ outpatient per day.

\section{Results and discussion}

\section{Stock and flow diagram}

Figure 2 shows the stock and flow diagram of hospital waste. The model encompasses three types: private, charitable, and government hospitals in the city of Nablus Palestine. Each hospital has both inpatients and outpatients. The model shows the waste generated from the three types of hospitals (private, charitable, and government). The model also classifies hospital waste into both general and hazardous wastes. The model considers the population as the main driver for determining the inpatients and outpatients for each type of hospital. As shown in the model, the hospital waste stock accumulates waste from inpatients and outpatients of government hospitals, private hospitals, and charitable hospitals. The accumulated waste is then filtered into two main types, namely, general 
waste and hazardous waste. The amount of hazardous waste is determined from the product of infectious waste fraction and hospital waste. The infectious rate is obtained from the case study as an average of the infectious waste from the total waste. General waste is the remainder of the total waste after subtracting the hazardous waste. The hazardous waste is either treated or disposed of or left untreated. The general waste is also either treated or disposed of. Table 3 exhibits the number of patients (inpatient, outpatient) in the private hospital on a yearly basis along with their yearly waste generated rate for the subsequent 12 years.

Table 3 Annual total hospital waste generated in the private hospitals (kg/year)

\begin{tabular}{rrlll}
\hline Years & $\begin{array}{l}\text { Private } \\
\text { inpatient }\end{array}$ & $\begin{array}{l}\text { Private } \\
\text { outpatient }\end{array}$ & $\begin{array}{l}\text { Private } \\
\text { inpatient } \\
\text { gen rate }\end{array}$ & $\begin{array}{l}\text { Private } \\
\text { outpatient } \\
\text { gen rate }\end{array}$ \\
\hline 1 & 8603 & 17,206 & 63,614 & 56,303 \\
2 & 8933 & 17,866 & 66,053 & 58,462 \\
3 & 9275 & 18,551 & 68,586 & 60,703 \\
4 & 9631 & 19,262 & 71,215 & 63,031 \\
5 & 10,000 & 20,000 & 73,946 & 65,447 \\
6 & 10,384 & 20,767 & 76,781 & 67,957 \\
7 & 10,782 & 21,563 & 79,724 & 70,562 \\
8 & 11,195 & 22,390 & 82,781 & 73,267 \\
9 & 11,624 & 23,248 & 85,955 & 76,076 \\
10 & 12,070 & 24,140 & 89,250 & 78,993 \\
11 & 12,533 & 25,065 & 92,672 & 82,021 \\
12 & 13,013 & 26,026 & 96,225 & 85,166 \\
\hline
\end{tabular}

The numbers of inpatients and outpatients are obtained for the case study on a daily basis and converted into a yearly basis and fed into the stock and flow model to generate future generated quantities. Table 4 is the same as Table 3, however, it considers the charitable hospitals, showing (inpatient, outpatient) on a yearly basis along with their yearly waste generated rate for the subsequent 12 years.

Table 4 Annual total hospital waste generated in charitable hospitals ( $\mathrm{kg} / \mathrm{year}$ )

\begin{tabular}{rrrll}
\hline Years & $\begin{array}{l}\text { Charitable } \\
\text { inpatient }\end{array}$ & $\begin{array}{l}\text { Charitable } \\
\text { outpatient }\end{array}$ & $\begin{array}{l}\text { Charitable } \\
\text { inpatient } \\
\text { gen rate }\end{array}$ & $\begin{array}{l}\text { Charitable } \\
\text { outpatient } \\
\text { gen rate }\end{array}$ \\
\hline 1 & 8229 & 12,343 & $35,769.68$ & $26,284.68$ \\
2 & 8544 & 12,817 & $37,141.06$ & $27,292.42$ \\
3 & 8872 & 13,308 & $38,565.02$ & $28,338.79$ \\
4 & 9212 & 13,818 & $40,043.57$ & $29,425.27$ \\
5 & 9565 & 14,348 & $41,578.81$ & $30,553.41$ \\
6 & 9932 & 14,898 & $43,172.90$ & $31,724.81$ \\
7 & 10,313 & 15,469 & $44,828.12$ & $32,941.11$ \\
8 & 10,708 & 16,062 & $46,546.79$ & $34,204.05$ \\
9 & 11,119 & 16,678 & $48,331.36$ & $35,515.40$ \\
10 & 11,545 & 17,318 & $50,184.34$ & $36,877.03$ \\
11 & 11,988 & 17,982 & $52,108.37$ & $38,290.87$ \\
12 & 12,447 & 18,671 & $54,106.16$ & $39,758.91$ \\
\hline
\end{tabular}

It is noticed from the above two tables that the numbers of both inpatients and outpatients in private hospitals are more than the charitable hospitals and also the annual waste generation rates. Table 5 portrays the government hospitals showing the inpatients and the outpatients along with 
their generation rates on a yearly basis. For example, in the first year, the inpatients and outpatients are 37,404 and $306,714 \mathrm{~kg}$, respectively.

Table 5 Annual total hospital waste generated in governmental hospitals ( $\mathrm{kg} / \mathrm{year}$ )

\begin{tabular}{rllll}
\hline Years & $\begin{array}{l}\text { Gov } \\
\text { inpatient }\end{array}$ & $\begin{array}{l}\text { Gov } \\
\text { outpatient }\end{array}$ & $\begin{array}{l}\text { Gov } \\
\text { inpatient } \\
\text { gen rate }\end{array}$ & $\begin{array}{l}\text { Gov } \\
\text { outpatient } \\
\text { rate }\end{array}$ \\
\hline 1 & 37,404 & 306,714 & 74,170 & 194,742 \\
2 & 38,838 & 318,474 & 77,014 & 202,208 \\
3 & 40,327 & 330,684 & 79,966 & 209,961 \\
4 & 41,873 & 343,362 & 83,032 & 218,010 \\
5 & 43,479 & 356,526 & 86,215 & 226,369 \\
6 & 45,146 & 370,195 & 89,521 & 235,048 \\
7 & 46,877 & 384,388 & 92,953 & 244,059 \\
8 & 48,674 & 399,125 & 96,517 & 253,416 \\
9 & 50,540 & 414,427 & 100,217 & 263,132 \\
10 & 52,478 & 430,316 & 104,059 & 273,220 \\
11 & 54,490 & 446,814 & 108,049 & 283,695 \\
12 & 56,579 & 463,944 & 112,192 & 294,572 \\
\hline
\end{tabular}

Table 6 Annual total hospital, general and hazardous wastes generated in four hospitals in Nablus city (kg/year)

\begin{tabular}{rllllr}
\hline $\begin{array}{r}\text { Years } \\
\end{array}$ & $\begin{array}{l}\text { Hospital } \\
\text { waste }\end{array}$ & $\begin{array}{l}\text { General } \\
\text { waste }\end{array}$ & $\begin{array}{l}\text { Hazardous } \\
\text { waste }\end{array}$ & $\begin{array}{l}\text { Waste } \\
\text { disposed }\end{array}$ & Treated \\
\hline 1 & 309,241 & 96,327 & 23,265 & 17,114 & 987 \\
2 & 418,943 & 250,887 & 54,563 & 153,636 & 8205 \\
3 & 465,964 & 355,728 & 72,058 & 408,362 & 20,613 \\
4 & 493,624 & 418,227 & 81,145 & 737,981 & 35,791 \\
5 & 515,649 & 457,111 & 86,621 & $1,112,344$ & 52,464 \\
6 & 536,399 & 484,780 & 90,782 & $1,515,732$ & 70,111 \\
7 & 557,274 & 507,725 & 94,551 & $1,941,002$ & 88,552 \\
8 & 578,738 & 529,024 & 98,273 & $2,385,307$ & 107,741 \\
9 & 600,957 & 550,065 & 102,073 & $2,847,784$ & 127,679 \\
10 & 624,007 & 571,465 & 105,997 & $3,328,461$ & 148,385 \\
11 & 647,934 & 593,500 & 110,064 & $3,827,758$ & 169,887 \\
12 & 672,777 & 616,306 & 114,285 & $4,346,275$ & 192,214 \\
\hline
\end{tabular}

Table 6 shows the total hospital waste, general, and hazardous wastes generated from the hospitals (private, charitable, and governmental) in Nablus city. The model also shows how much waste is disposed of and treated each year. The model considered the mean hazardous to non-hazardous waste, which is nearly 0.203 . This percentage is almost equal if it is compared with a study conducted by Patil and Pokhrel (2005), which shows the percentage of hazardous to non-hazardous waste as 0.19 , while this percentage is quite large if it is compared with a study conducted by Rao et al. (2004), which shows the percentage of hazardous to non-hazardous waste as 0.10 for all types of hospitals (government, private, and charitable). This leads to a question of why it is larger than India, while Palestine and India are both developing countries. Is it because of rigorous legislation and rules or the classification of hazardous to non-hazardous is different. According to Matin (2006), hazardous medical waste should be carefully separated at the point of generation from the nonhazardous waste to minimize the management costs mainly of handling and treatment. 


\section{Conclusions}

This research shows that system dynamics modelling can provide a more comprehensive and sophisticated simulation method for the forecasting of hospital waste. The developed stock and flow model differentiates between private, charitable, and government hospitals, according to the level of service. The level of service determines the type of hospital: private, government, or charitable establishment. Each hospital has two types of patients, namely, inpatients and outpatients, both of which generate waste. The Systems Dynamics model is generic and could be used in any country to simulate waste generation according to the level of service. The model can help waste planners to optimize waste management systems related to environmental protection. It is shown that the waste treated fraction is affected by staff training and the enforcement of legislation. The amount of waste treated could be increased, consequently reducing the health risks and improving public health. The level of service in the private hospital was much better than the government hospital, which leads to excess of waste generation. For example, the hazardous waste generation in the private hospital per inpatient is $1.64 \mathrm{~kg}$ per day, while the hazardous waste generation in the government hospital is $0.293 \mathrm{~kg}$ per day. The amount of hazardous waste correspondsto20.322.3\%ofthetotalwastestreamscollected from the four hospitals, and the higher percentage was from the private hospital. The model also calculates the total waste generated from both private and government hospitals together with differentiating between general and hazardous waste. Health risks increase due to the increasing quantity of untreated hazardous hospital waste.

\section{Acknowledgments}

The authors are thankful and acknowledge the financial support by the research committee and academic affairs at Birzeit University, Palestine. Also, many thanks to all those who have facilitated the work of data collection in Nablus city hospitals.

\section{References}

Abd El-Salam, M. M. (2010). Hospital waste management in ElBeheira Governorate, Egypt. Journal of Environmental Management, 91(3), 618-629.

Alagöz, A. Z., \& Kocasoy, G. (2008). Determination of the best appropriate management methods for the health-care wastes in Istanbul. Waste Management, 28(7), 1227-1235.

Askarian, M.,Heidarpoor, P.,\& Assadian, O.(2010). A total quality management approach to healthcare waste management in Namazi hospital, Iran. Waste Management,30(11),2321-2326.

Bach, N.L.,\& Saeed,K. (1992). Food self-sufficiency in Vietnam: a search for a viable solution. System Dynamics Review, 8, 129-148.

Bala, B. K. (1999). Principles of system dynamics. Udaipur: Agrotech Publishing Academy.

Bdour, A., Altrabsheh, B., Hadadin, N., \& Al-Shareif, M. (2007). Assessment of medical wastes management practice: a case study of the northern part of Jordan. Waste Management,27,746-759.

Bendjoudi, Z., Taleb, F., Abdelmalek, F., \& Addou, A. (2009). Healthcare waste management in Algeria and Mostaganem department. Waste Management, 29(4), 1383-1387. 
Birpinar, M. E., Bilgili, M. S., \& Erdoğan, T. (2009). Medical waste management in Turkey: a case study of Istanbul. Waste Management, 29, $445-448$.

Blenkharn, J. (2006). Lowering standards of clinical waste management-do the hazardous waste regulations conflict with CDC universal precautions? Journal of Hospital Infection, 62, 467-472.

Chaerul, M., Tanaka, M., \& Shekdar, A. V. (2008). A system dynamics approach for hospital waste management. Waste Management, 28(2), 442-449.

Cheng, Y. W., Li, K. C., \& Sung, F. C. (2010). Medical waste generation in selected clinical facilities in Taiwan. Waste Management, 30, 1690-1695.

Cheng, Y.W., Sung, F.C., Yang, Y., Lo, Y.H., Chung, Y.T.,\& Li, K. C. (2009). Medical waste production at hospitals and associated factors. Waste Management, 29, $440-444$.

Ciplak, N., \& Barton, J. (2012). A system dynamics approach for healthcare waste management: a case study in Istanbul Metropolitan City, Turkey. Waste Management \& Research, 3(6), 576-586.

Debere, M. K., Gelaye, K. A., Alamdo, A. G., \& Trif, Z. M. (2013). Assessment of the health care waste generation rates and its management system in hospitals of Addis Ababa, Ethiopia, 2011. BMC Public Health, 13,1-9.

DEFRA (Department for Environment, Food and Rural Affairs) (2005). Hazardous waste regulations. London: Her Majesty's Stationery Office.

Drew, D.R.(1990). Modeling strategies for promoting agricultural development. In: Proceedings of the International Agricultural Engineering Conference and Exhibition. Bangkok, Thailand, 3-6 December 1990.

Forrester, J.W. (1971). World dynamics. Wright-Allen Press, MIT Massachusetts.

Haylamicheal, I.D.,Dalvie,M.A., Yirsaw, B.D.,\& Zegeye, H.A. (2011). Assessing the management of healthcare waste in Hawassa city, Ethiopia. Waste Management \& Research, 29(8), 854-862.

Health and Safety Executive (HSE) (2008). Health and safety training: guidelines for the waste management and recycling industry. Retrieved on 18 January 2013 from: http://www. hse.gov.uk/pubns/waste21.pdf.

Hossain, M.S., Santhanam, A., NikNorulaini, N.A.,\& Omar, A. K. (2011). Clinical solid waste management practices and its impact on human health and environment-a review. Waste Management, 31(4), 754-766.

High Performance System (HPS) (1996). Stella, Inc., USA. Available from: http://www.hpsinc.com/stellavpsr.htm. Accessed 26 February 2016.

Khalaf, A.A.(2009). Assessment of medical waste management in Jenin district hospitals. Master thesis, Annajah National University, Nablus, Palestine.

Lee, B.-K., Ellenbecker, M. J., \& Moure-Ersaso, R. (2004). Alternatives for treatment and disposal cost reduction of regulated medical wastes. WasteManagement,24(2),143-151. 
Manga, V. E., Forton, O. T., Mofor, L. A., \& Woodard, R. (2011). Health care waste management in Cameroon: a case study from the south-western region. Resources, Conservation and Recycling, 57, $108-116$.

Matin, K. (2006). University of California, Irvine Medical Waste Management Plan, pp.1-5. April 15, 2008.

Mashayekhi, A.N.(1990).Rangel and destruction under population growth: the case of Iran. System Dynamics Review, 6,167-193.

Meadows, D. H., Meadows, D. L., \& Randers, J. (1992). Beyond limits. Vermont: Chelsea Green Publishing. Ministry of Health (2012) Annual report. Ramallah, Palestine.

Mohamed, L. F., Ebrahim, S. A., \& Al-Thukair, A. A. (2009). Hazardous healthcare waste management in the Kingdom of Bahrain. Waste Management, 29, $2404-2409$.

Olko, P.,Winch, R.(2002). Introducing waste segregation. Health Estate Journal, 56(10), 29-31.

Patil, G. V., \& Pokhrel, K. (2005). Biomedical solid waste management in an Indian hospital: a case study. Waste Management, 25, $592-599$.

Patwary, M. A., O'Hare, W. T., \& Sarker, M. H. (2011). Assessment of occupational and environmental safety associated with medical waste disposal in developing countries: a qualitative approach. Safety Science, 49(8-9), 1200-1207.

Prem Ananth, A., Prashanthini, V., \& Visvanathan, C. (2010). Healthcare waste management in Asia. Waste Management, 30(1), 154-161.

Pruss-Ustun, A., Rapiti, E., \& Hutin, Y. (2005). Estimation of the global burden of disease attributable to contaminated sharps injuries among health-care workers. American Journal of Industrial Medicine, 48,482-490.

Rao, L., Ranyal, W., Bhatia, L.,\& Sharma, L. (2004).Biomedical waste management: an infrastructural survey of hospitals. Medical Journal Armed Forces India, 60, 379 -382.

Saeed, K.(1994). Development planning and policy design: a system dynamics approach. Vermont: Chelsea Green Publishing.

Saysel, A. K., \& Barlas, Y. (2001). A dynamic model of salinization on irrigated lands. Ecological Modelling,139, 177-199.

Shiferaw, Y., Abebe, T., \& Mihret, A. (2012). Sharps injuries and exposure to blood and bloodstained body fluids involving medical waste handlers. Waste Management \& Research, 30(12), 1299-1305.

Sudhir, V., Srinivasan, G., \& Muraleedharan, V. R. (1997). Planning for sustainable solid waste management in urban India. System Dynamics Review, 13(3), 223-246.

Sufian, M.A.(2001). Planning for urban solid waste management: the case of Dhaka City. Unpublished M.S. Thesis, Dept. of Farm Power \& Machinery, Bangladesh Agricultural University, Mymensingh, December 2001. 
Taghipoura, H., \& Mosaferi, M. (2009). Characterization of medical waste from hospitals in Tabriz, Iran. Science of the Total Environment, 407, 1527 -1535.

Yong, Z., Gang, X., Guanxing, W., Tao, Z., \& Dawei, J. (2009). Medical waste management in China: a case study of Nanjing. Waste Management, 29, 1376-1382. 